\title{
Habilidades tecnológicas e ensino superior em Jornalismo no Brasil: observação das exigências contemporâneas e seu contraste com as grades curriculares $0^{1}$
}

\section{Walter Teixeira Lima Júnior e André Rosa de Oliveira}

\section{Resumo}

0 artigo destaca as mudanças nas rotinas de produção da notícia impetradas pela evolução tecnológica, relacionando-as com a estrutura atual dos cursos de Jornalismo. Para isso, foi realizada uma observação das disciplinas oferecidas por instituições apontadas como as melhores, segundo rankings especializados. Apresenta ainda uma síntese de ideias sobre o que é preciso para formar um profissional em Jornalismo, tendo como pano de fundo o desenvolvimento de uma Teoria do Jornalismo no país e as fronteiras com as múltiplas possibilidades de atuação profissional. A partir destas premissas, aponta: o profissional que produz informação de relevância social nas tecnologias digitais conectadas está se afastando do espaço de importância e referência social, devido ao seu uso de forma doméstica.

\section{Palavras-Chave}

Jornalismo. Tecnologia. Educação.

Walter Teixeira Lima Júnior I digital@walterlima.jor.br Doutor em Ciências da Comunicação (USP). Docente do Programa de Pós-graduação em Comunicação Social da Universidade Metodista de São Paulo.

André Rosa de Oliveira I andrerosa.jor@gmail.com Mestre em Comunicação (Cásper Líbero). Professor das Faculdades Integradas Rio Branco. Doutorando da Universidade Metodista de São Paulo.

\section{Apresentação}

As oportunidades de empregos no campo do Jornalismo demonstram a modificação no escopo profissional solicitado para quem deseja trabalhar em uma redação integrada ou convergente. Desde a implantação dos computadores e depois das redes telemáticas nas redações, as habilidades requeridas aumentaram, principalmente na compreensão sobre 0 funcionamento e possibilidades tecnológicas. Assim, está tornando-se comum, entre jornalistas interessados no movimento do mercado, encontrarem ofertas de emprego mencionando qualidades antes não requeridas. 0 The Dallas Morning News ${ }^{2}$ não deseja somente encontrar profissional que realize as atividades de redator, editor ou outro cargo com atributos tradicionais. A publicação estadunidense quer um newsroom data specialist - em uma tradução livre, especialista em dados para a redação.

Este especialista seria responsável por colher e analisar dados com um foco em respostas rápidas em reportagens investigativas e de fiscalização 
(watchdog). Trabalharia gerenciando a biblioteca de dados da redação e contribuindo para "tecer melhores histórias". Entre as habilidades exigidas ou desejáveis, temos: Excel avançado, SQL, limpeza de dados, mídias sociais, análises estatísticas, sistemas de informação geográficos e visualização de dados.

\section{Já 0 tradicional The New York Times ${ }^{3}$ procura} por um Editor de Plataformas Digitais. Exige, além de fortes conhecimentos na área da informação de relevância social e "demonstrar forte paixão com o jornalismo em todas as formas", habilidades tecnológicas, como "excepcionais conhecimentos de informática, incluindo proficiência em HTML, CSS e Javascript". 0 inglês The Guardian ${ }^{4}$, pioneiro no trabalho com base de dados abertas, procura especialista em interatividade e dados. Entre as responsabilidades do profissional, está a "geração de notícias baseadas em dados, blogposts e gráficos interativos, colocando-as no ar tão rapidamente e acessível quanto possível a partir de uma variedade de fontes".
Estas novas oportunidades sinalizam que as habilidades necessárias, em algumas funções emergentes no Jornalismo produzido para as plataformas digitais conectadas, se aproximam do conhecimento profissional das tecnologias relacionadas a banco de dados e linguagens de programação. Assim, depois do campo do Jornalismo ser impactado com a introdução dos computadores nas redações, anos 1970 nos EUA e 1980 no Brasil, dos profissionais se adaptarem às possibilidades de comunicação descentralizada e de baixa hierarquia da Internet (BARAN, 1964) nos anos 1990 (e-mail, blogs, redes sociais, etc.), e na fase atual tecnológica, com 0 aprofundamento nas linguagens ligadas aos bancos de dados sendo requeridas, uma nova fase se estabelece. Ela aponta para que profissionais de Jornalismo não só possuam conhecimentos domésticos sobre as tecnologias digitais conectadas, mas devem também possuir conhecimento das tecnologias que estruturam, acessam, relacionam e visualizam dados a partir de bases abertas ou fechadas.

Trabalho apresentado no XVIII Congresso de Ciências da Comunicação na Região Sudeste (Bauru - SP), em 04/07/2013.

Anúncio que circulou por e-mail em listas especializadas em dezembro de 2012: “*Newsroom data specialist*: The Dallas Morning News is hiring a newsroom data specialist to gather and analyze data with a focus on quick-hit investigations and watchdog stories. The data specialist will work with reporters across the newsroom, usually in a supporting role, to spin data straw into journalism gold. As part of a three-person data squad on the paper's investigative projects team, the specialist also manages the newsroom'ss extensive data library with the assistance of the data intern. The data specialist must have at least three years of journalism experience (preferably at a metro paper) including the use of open records requests and negotiating for data. The following skills are required: advanced Excel, SQL and data cleaning. Candidates with experience in social media, statistical analysis, geographic information systems or data visualization are preferred. Please e-mail resume, cover letter and clips of stories where you did the data analysis to: dlathrop@dallasnews.com".

Disponível em <http://jobs.nytco.com/job/New-York-Digital-Platforms-Editor-Job-NY/2069537/>, acesso em 28.fev.13.

Disponivel em <http://gs10.globalsuccessor.com/fe/tpl_GuardianNews01.asp?newms=jj\&id=94455\&aid=13972>, acesso em 28.fev.13. 
As descrições anteriores reacendem a reflexão a respeito do perfil profissional de quem lida com a notícia: as plataformas digitais de publicação e distribuição de conteúdo abrem caminho para novas reconfigurações possíveis em uma redação. Visões de que o futuro do Jornalismo está nas mãos de quem se dispõe a entender como as tecnologias funcionam proliferam (BRIGGS, 2010; ROYAL, 2010). Mas não somente os pesquisadores da área do Jornalismo apontam esse caminho. Para 0 cientista Tim BernersLee, inventor do WWW e mentor do consórcio W3C, afirma que "os jornalistas devem ser especialistas em banco de dados" ${ }^{\prime \prime}$.

A apropriação de novas tecnologias computacionais trouxe a possibilidade de explorar novos métodos, contribuindo para o fortalecimento de conceitos clássicos - podemos definir este cruzamento de ideias como Jornalismo Computacional (HAMILTON; TURNER, 2010). Isso inclui habilidades computacionais e capacidade de extrair informações não triviais em grandes bases de dados e, se possível, transformá-las em narrativas visualmente amigáveis (LIMA JUNIOR, 2011).

Mudanças nas rotinas de produção afetam diretamente como os cursos de Jornalismo estão estruturando as suas matrizes curriculares para entrar em sintonia com as necessidades informativas da sociedade contemporânea. Desde a introdução das tecnologias digitais nos processos de produção do Jornalismo, as modificações são bastante discutidas e combatidas. Portanto, não se trata de um debate simples, mas, sim, de um intrincado labirinto formado por questões relacionadas desde a consolidação dos cursos de Comunicação Social no Brasil, nos anos 1960, até a decisão do Supremo Tribunal Federal, em 2009, que extinguiu a exigência do diploma para o exercício da profissão de jornalista. Se, por um lado, há uma visível crise na formação, novas possibilidades de pesquisa e desenvolvimento profissional se revelam a partir da tecnologia.

Este artigo abre caminhos possíveis a partir das possibilidades oferecidas pelas universidades brasileiras: será que o espaço designado a questões ligadas à tecnologia dá conta desta necessidade? 0 estudo faz uma observação das disciplinas oferecidas nos cursos de Jornalismo relacionadas às tecnologias digitais conectadas, por meio das suas nomenclaturas, de modo a identificar se: 1) sinalizam adaptação ao novo cenário das habilidades profissionais; 2) estão apenas sintonizadas à fase da produção do Jornalismo, quando os profissionais utilizam as tecnologias digitais conectadas de forma doméstica (e-mail, redes sociais, blogs); 3) são reflexo das necessidades atuais do Jornalismo praticado nas plataformas digitais conectadas pelos veículos de comunicação brasileiros. 


\section{Formação do jornalista no Brasil}

Walter Lippmann, que já nos anos 1920 delineou

o Modelo Padrão de Jornalismo Profissional, dizia que "o povo só conhece o mundo de forma indireta, através de imagens incompletas marcadas pelas irremediáveis fraquezas da imprensa" (KOVACH; ROSENSTIEL, 2003, p. 43). Se a visão do Jornalismo a serviço de uma sociedade democrática para a construção da cidadania parecia falha no início do século passado, enfraqueceu com a TV a cabo e a Internet. Para Jack Fuller (2010, p.2), no final da primeira década do XX, alguns princípios delineados por Lippman já estavam se diluindo. "É claro, o fator que leva a remodelar 0 ambiente de informação, de que a notícia é uma pequena parte, tem sido a tecnologia" (FULLER, 2010, p. 2).

Tal percepção, bem como a desconfiança do público diante da mídia desencadearam discussões dedicadas ao Jornalismo, como os encontros regulares do chamado Committee of Concerned Journalists (KOVACH; ROSENSTIEL, 2003) a partir de 1997. Na mesma linha, em agosto de 2012, um grupo de fundações norteamericanas compartilhou, por meio da Knight Foundation, uma carta aberta a universidades ${ }^{6}$. Segundo seus signatários, as escolas que não se reinventarem, especialmente ao integrar inovações aos seus currículos e oferecer aos alunos mais flexibilidade para fazer cursos em áreas como tecnologia e empreendedorismo, ficarão para trás.

No Brasil, historicamente, não há acordo sobre o conjunto de princípios que permitam definir quem é o jornalista e como ele deve pautar o seu comportamento (ALBUQUERQUE, 2004). RAMADAN (2004) já observava, em 1995, evidências de que o curso de Jornalismo apresentava falhas na formação de novos profissionais, problema que se acentua diante de novidades tecnológicas que exigem novos conceitos e linhas de trabalho.

Recentemente, no entanto, houve um esforço para tal. Em 2009, uma comissão de professores foi nomeada pelo Ministério da Educação, com a missão de redefinir as diretrizes curriculares para o curso de Jornalismo. Este relatório, aprovado pelo Conselho Nacional de Educação e homologado pelo MEC, é uma síntese da experiência acadêmica nacional acerca do que é preciso para formar um jornalista.

Este deve ser dotado de competência teórica, técnica, tecnológica, ética e estética para atuar criticamente e de modo responsável. Isso vai além das especificidades da profissão: engloba tanto uma fundamentação humanística quanto técnicas específicas, abrangendo estímulo a investigações sobre inovações tecnológicas e 
atividades práticas em múltiplos suportes "para atuar num contexto de mutação tecnológica constante no qual, além de dominar as técnicas e as ferramentas contemporâneas, é preciso conhecer os seus princípios para transformálas na medida das exigências do presente" (COMISSÃO DE ESPECIALISTAS, 2009).

0 documento ressalta a construção de uma matriz pedagógica ao redor do curso de Jornalismo ao longo dos últimos 60 anos, mesclando o padrão teórico europeu ao pragmatismo norte-americano na formação de um profissional "crítico-experimental" apesar da constatação de pesquisadores como MEDITSCH (1999) de que a escola norteamericana define os paradigmas da profissão que serão imitados em todo 0 mundo.

Diante deste cenário, o que se espera de um jornalista? Para uma pergunta simples, 0 pesquisador alemão Michael Kunczik sugere uma resposta não menos direta: "0 jornalista nasce feito, não se faz". A crença de que "pessoas nascem com esse talento e que aptidões não podem ser aprendidas" é, segundo o autor, uma das causas para a formação ser mais ou menos subestimada, mesmo que investigações não puderam ser capazes de estabelecer especificamente o que é "talento jornalístico". Ao mesmo tempo, forjá-los em uma redação sugerindo que 0 aprendizado não corresponde ao que acontece no dia a dia aponta para um resultado semelhante, o que gera insatisfação, tensão e conflito (KUNCZIK, 1997, p. 386).

0 distanciamento entre 0 que se faz e 0 que se ensina pauta o desenvolvimento de uma Teoria do Jornalismo no Brasil. 0 livro Ideologia e Técnica da Notícia, de Nilson Lage, publicado em 1979, é considerado um marco: antes dele, a bibliografia sobre 0 assunto ou sistematizava a práxis sem explicar fenômenos ou via a profissão sob uma grossa lente teórico-crítica. A partir deste livro, Adelmo Genro Filho publicou, em 1987, O Segredo da Pirâmide. Ambos são considerados precursores da área e tratam da relação entre teoria e prática do "filho mais legítimo desse casamento entre o novo tecido universal das relações sociais produzido pelo advento do capitalismo e os meios industriais de difundir informações" (GENRO FILHO, 1987).

Por ser uma transmissão sistemática a partir da emergência do capitalismo, a natureza da informação, segundo o autor gaúcho, deve ser claramente delimitada. Afinal, profissionais que incorporam os interesses do veículo onde atuam emprestam seu "talento, honestidade e ingenuidade a serviço do capital com a mesma naturalidade com que compram cigarros no bar da esquina" (GENRO FILHO, 1987). 0 contexto pós-militarismo em seu discurso não é o mesmo, mas sua visão permanece atual.

Existe uma grande defasagem entre a atividade jornalística e as teorizações que se fazem em torno dela. Esse distanciamento se dá em tal grau que, inclusive, tem gerado falsas e absur- 
das polêmicas opondo "teóricos" e "práticos"... Essa polarização torna-se a expressão de um diálogo, não de surdos, mas de mudos: um não consegue falar ao outro. A prática, por sua limitação natural, jamais soluciona a teoria. Ela apenas insiste, através de suas evidências e contradições, que deve ser ouvida. Mas só pode se expressar racionalmente através da teoria. (GENRO FILHO, 1987)

As novas diretrizes curriculares pedem ainda um tratamento diferenciado para o curso, que deverá se chamar Bacharelado em Jornalismo. Entre as razões para tal, aponta uma justificativa histórica: nos anos 1960, dentro do contexto da ditadura militar, o país adotou um modelo que prevê um único curso (Comunicação Social), distintas habilitações e a formação de um tipo de "comunicador polivalente". Este caminho contribuiu para este afastamento entre os caminhos da teoria e da prática.

\begin{abstract}
Neste processo, os estudantes que passam por nossos cursos são obrigados a uma opção dramática: ou desprezam a teoria ensinada $\mathrm{e}$ reafirmam a vocação profissional que os levou à faculdade, desenvolvendo uma forte resistência à atividade teórica, ou abandonam a vocação inicial e tornam-se "comunicadores" sem mercado de trabalho e sem prática, só encontrando colocação na própria universidade como "comunicólogos". (MEDITSCH, 1999)
\end{abstract}

Contudo, outras variáveis também afetaram profundamente 0 ensino do Jornalismo: a revolução digital da informação com 0 advento dos computadores pessoais e o surgimento de redes telemáticas (Bulletin Board System, Videotexto e Internet).

\section{Tecnologia e Jornalismo}

0 documento que baliza reformulações curriculares a partir de 2014 apresenta 0 "diagnóstico de um mundo caracterizado pela capacidade discursiva das organizações e dos cidadãos", mesclado a "eventos transformadores no ritmo vigoroso da instantaneidade". É preciso dar conta das exigências contemporâneas e ampliar a atuação profissional em novos campos, projetando a função social da profissão em contextos ainda não delineados no presente. Inserido em um novo ecossistema informativo digital conectado, "o profissional terá que adquirir novas habilidades, especialmente no campo tecnológico. Entender como o meio se estrutura e utilizar suas características técnicas para retirar dele, com eficiência, um jornalismo de qualidade, primordial para a sociedade do futuro" (LIMA JUNIOR, 2003, p. 255).

Assim, além de aliar pensamento humanista e domínio de ferramentas, valoriza-se ainda o perfil de profissionais aptos a executarem múltiplas tarefas, com visão estratégica do negócio em que atua e capacidade de criar soluções inovadoras. Historicamente, no entanto, tem sido difícil - ou mesmo impossível - para um jornalista mostrar habilidades técnicas (DAGIRAL; PARASIE, 2011). A pretensão dos cursos de Jornalismo no Brasil em formar profissionais preparados para os desafios do mercado e, ao mesmo tempo, desenvolverem uma visão crítica e humanista, se 
torna ainda mais ampla. Isto é, ainda mais difícil de ser executada, aprofundando o fosso entre a realidade profissional e os pressupostos da sua formação (DIB et al, 2010).

Além da dificuldade em delimitar funções e atribuições ao profissional envolto em possibilidades, os debates relacionados à adoção de novas tecnologias - que ocorre desde a apropriação do rádio e da televisão, lembra KUNCZIK (1997, p. 209) - começaram em um nível político: defensores e opositores se limitavam a promover os aspectos positivos ou negativos. Outro exemplo, já envolvendo o uso de computadores, está na reportagem assistida por computador (conhecida pela sigla RAC). Mark Briggs salienta que o formato, desenvolvido de forma pioneira por Phillip Meyer ao final dos anos 1960, era restrito ao jornalismo impresso, mas na web pode ser aprofundado, customizado, rastreável e ter vida longa (2010, p. 255).

Kunczik, no entanto, vê limites: esta prática requer treinamento intensivo nas técnicas da ciência social empírica, que inclui 0 levantamento de informações, sua análise e interpretação. Na ausência desta habilidade, há um grande risco em fazer uma interpretação equivocada e, consequentemente, produzir informação incorreta. Assim, das duas, uma: ou a investigação sociocientífica não pode ser tarefa do Jornalismo; ou é preciso melhorar de forma geral o nível de conhecimentos sociocientíficos básicos dos jornalistas (1997, p. 209).
Seja como for, a prática do jornalismo a partir da mineração de dados já é uma realidade, tanto como objeto de pesquisa (LIMA JUNIOR, 2012) como nas redações. ZANCHELLI E CRUCIANELLI (2013) fizeram um levantamento estrutural em redações que adotam práticas envolvendo dados e Jornalismo. As melhores práticas estão relacionadas à proximidade entre desenvolvedores e repórteres - tanto nas mesas quanto no planejamento de ideias; produção de histórias que demonstrem a importância de dados; e, finalmente, contratação de profissionais que facilitem a construção dessa ponte.

Para ampliar este contexto, a Columbia Journalism School, por meio do Tow Center for Digital Journalism, apresentou um amplo relatório sobre o cenário atual do jornalismo norte-americano. 0 documento, definido como uma mistura de pesquisa com manifesto (ANDERSON; BELL; SHIRKY, 2012), sugere recomendações neste momento denominado "pós-industrial". Com a nova relação entre 0 Jornalismo e seu público, capaz de provocar "mudanças tectônicas" e um cenário de incerteza, as rotinas e os modelos de negócios precisam ser repensados, bem como novas habilidades precisam ser aprendidas constantemente pelos profissionais para garantir sua sobrevivência.

A divulgação do relatório provocou respostas. Em artigo publicado pelo The Guardian 7 , a professora Eugenia Siapera vai além da visão 
dos professores de Columbia: ao invés de táticas de sobrevivência, o Jornalismo precisa de uma estratégia mais radical para permanecer socialmente relevante. No Brasil, Carlos Castilho, do Observatório da Imprensa ${ }^{8}$, reforça a importância de uma visão multidisciplinar dos profissionais, "uma mudança de rotina e de valores que vai gerar bastante desconforto na maioria dos jornalistas, porque sabemos que a relação deles com a universidade é complicada e cheia de queixas mútuas".

Uma postura possível para universidades está em ultrapassar as fronteiras da tecnologia como um "suporte técnico ao trabalho das disciplinas de humanas" e repensar cursos a partir do "código-fonte" correspondente a cada projeto - repensar suas estruturas tradicionais ao softwerizar conceitos, como forma de fortalecer o pensamento (BERRY, 2011). Exemplo prático deste cruzamento é a realização do Computation + Journalism Symposium pelo Georgia Tech College of Computing ${ }^{9}$, que, em sua segunda edição, reuniu 150 profissionais - tanto programadores quanto jornalistas.

No entanto, MEDITSCH (1999), citando o livro Imposturas Intelectuais, em que os físicos Alan
Sokal e Jean Bricmont lutam contra a proliferação de ideias confusas e obscuras pautado por um pensamento pós-moderno, faz um alerta a este processo: a conquista da competência tecnológica passa por um aprofundamento e rigor científico metaforicamente, "crescer para cima", ao invés de "expandir para os lados".

A lógica política é aquela da conquista de territórios e do acúmulo de poder. Seguindo esta lógica, o campo que era do jornalismo abocanhou não só as outras profissões da área de comunicação como, uma vez transformado em campo da comunicação, pretendeu dominar um objeto tão amplo que vai do estudo do amor à explicação da sociedade, da cultura $\mathrm{e}$ da civilização contemporâneas. Por este caminho, chegamos ao sexo dos anjos, e como o campo é tão amplo que não há metodologia que 0 abarque, estamos nos afastando do rigor científico na mesma proporção em que queremos explicar mais e mais coisas, e nos caracterizando perigosamente como um terreno fértil para as imposturas intelectuais denunciadas por Sokal. (MEDITSCH, 1999)

Assim, as questões alertadas desafiam os professores e as direções dos cursos de Jornalismo para que sintonizem as disciplinas ligadas às tecnologias digitais conectadas com as necessidades informativas da sociedade contemporânea e habilitem os futuros jornalistas para exercerem as suas novas

"From post-industrial to post-journalism". Media Network, The Guardian, 14.fev.13. Disponível em <http://www.guardian.co.uk/ media-network/media-network-blog/2013/feb/14/post-industrial-journalism-changing-society>, acesso em 26.fev.13.

3 “0 jornalismo pós-industrial - parte 2". Código Aberto, Observatório da Imprensa, 02.jan.13. Disponível em <http://www. observatoriodaimprensa.com.br/posts/view/jornalismo_pos_industrial_2>, acesso em 26.fev.13.

"Finding tools vs. making tools: Discovering common ground between computer science and journalism", Nieman Journalism Lab, 14.fev.13. Disponível em <http://www.niemanlab.org/2013/02/finding-tools-vs-making-tools-discovering-commonground-between-computer-science-and-journalism>, acesso em 26.fev.13 
atribuições nas empresas de mídia ou como profissionais autônomos.

Por ora, a resposta das universidades está na incorporação das novas tecnologias com maior intensidade em seus currículos a partir dos anos 1990, mas mantendo uma forte divisão entre teóricos e práticos refratários à multidisciplinaridade, sem amadurecer um projeto pedagógico que relacione as instâncias prática e teórica às modificações que a profissão vem sofrendo (RAMADAN, 2004).

\section{Observação das grades curriculares}

Para checar a forma como os cursos de Jornalismo no Brasil lidam com novas tecnologias, foi realizada uma observação curricular de algumas instituições. A amostra das IES tomou como base os rankings Folha $\mathrm{RUF}^{10}$, a qual aponta, segundo seus critérios, as melhores do país na área de jornalismo, redação e conteúdo, além das universidades que receberam cinco ou quatro estrelas no ranking do Guia do Estudante, mantido pela Editora Abril ${ }^{11}$.

Foram excluídas as repetições, bem como duas IES listadas que não apresentavam dados satisfatórios: 0 curso de Jornalismo da FAAP aparece no ranking Folha RUF, mas a instituição oferece apenas cursos em nível de pós-graduação.

Já a PUC de Curitiba, mencionada pelo Guia do Estudante, apresenta em seu site apenas as disciplinas do primeiro semestre. Dessa forma, a amostra final reúne 39 cursos considerados os melhores do país, listados no Quadro 1.

Nenhuma das instituições listadas apresenta, de forma aberta, seus planos ou projetos pedagógicos, bem como o detalhamento do corpo docente, infraestrutura, articulação e fundamentação didático-pedagógica do curso, entre outras demandas administrativas. Estas informações são necessárias ao reconhecimento de cursos de graduação da área da Comunicação Social e devem ser providenciadas pelas instituições, especialmente em visitas periódicas do Ministério da Educação para avaliaçãa ${ }^{12}$. Dessa forma, os dados entre projeto e estrutura curricular são restritos ao relacionamento entre IES e MEC.

Assim, a observação proposta neste artigo leva em consideração informações disponíveis online. Os sites consultados oferecem ao visitante uma apresentação dos cursos, além das habilidades desejáveis ao egresso e grade de disciplinas. A nuvem de palavras apresentada na Figura 1 reúne os 100 termos mais comuns nos textos introdutórios: quanto maior o tamanho do termo, mais comum sua presença. 0 resultado corrobora

10 Lista disponível no site <http://ruf.folha.uol.com.br/rankings/rankingporcursos>, acesso em 16.jan.2013

11 Lista disponível no site <http://guiadoestudante.abril.com.br/universidades>, acesso em 16.jan.2013

12 Padrões de Qualidade para Cursos da área de Comunicação Social. Disponível em <http://portal.mec.gov.br/sesu/arquivos/pdf/ rjornalismo.pdf $>$. Acesso em 19.abr.2015. 
Quadro 1: Lista de cursos observados

\begin{tabular}{|c|c|c|c|}
\hline IES & UF & IES abreviada & URL \\
\hline Universidade Anhembi Morumbi & SP & ANHEMBI & http://www.anhembi.br \\
\hline Faculdade Cásper Líbero & SP & CASPER & http://www.casperlibero.edu.br \\
\hline Escola de Comunicações e Artes (ECA) - USP & SP & ECA-USP & http://www.eca.usp.br \\
\hline Escola Superior de Propaganda e Marketing & $\mathrm{SP}$ & ESPM & http://www.espm.br \\
\hline $\begin{array}{l}\text { Faculdade dos Meios de Comunicação Social (Famecos) - } \\
\text { PUCRS }\end{array}$ & RS & FAMECOS & http://www.pucrs.br \\
\hline Universidade Presbiteriana Mackenzie & SP & MACKENZIE & http://www.mackenzie.br \\
\hline Universidade Positivo & PR & POSITIVO & http://up.com.br \\
\hline Pontifícia Universidade Católica de Campinas & $\mathrm{SP}$ & PUC CAMP & http://www.puc-campinas.edu.br \\
\hline Faculdade de Comunicação e Artes - PUC Minas & MG & PUC MINAS & http://www.pucminas.br \\
\hline Pontifícia Universidade Católica do Rio de Janeiro & RJ & PUC RJ & http://www.puc-rio.br \\
\hline Pontifícia Universidade Católica & SP & PUC SP & http://www.pucsp.br \\
\hline Universidade Católica de Brasília & DF & UCB & http://www.ucb.br \\
\hline Universidade de Caxias do Sul & RS & UCS & http://www.ucs.br \\
\hline Universidade Estadual de Ponta Grossa & PR & UEPG & http://www.uepg.br \\
\hline Universidade do Estado do Rio de Janeiro & RJ & UERJ & http://www.uerj.br \\
\hline $\begin{array}{l}\text { Faculdade de Comunicação da Universidade } \\
\text { Federal da Bahia }\end{array}$ & $\mathrm{BA}$ & UFBA & http://www.ufba.br \\
\hline Universidade Federal do Ceará & CE & UFC & http://www.ufc.br \\
\hline Instituto de Arte e Comunicação Social - UFF & RJ & UFF & http://www.uff.br \\
\hline $\begin{array}{l}\text { Faculdade de Comunicação e Biblioteconomia - } \\
\text { FACOMB - UFG }\end{array}$ & G0 & UFG & http://www.ufg.br \\
\hline Faculdade de Comunicação - FACOM/UFJF & MG & UFJF & http://www.ufff.br \\
\hline Faculdade de Filosofia e Ciências Humanas (Fafich) - UFMG & MG & UFMG & http://www.ufmg.br \\
\hline Universidade Federal do Mato Grosso & MT & UFMT & http://www.ufmt.br \\
\hline Universidade Federal de Pernambuco & PE & UFPE & http://www.ufpe.br \\
\hline Universidade Federal do Piauí & $\mathrm{PI}$ & UFPI & http://www.ufpi.br \\
\hline Universidade Federal do Paraná & PR & UFPR & http://www.ufpr.br \\
\hline $\begin{array}{l}\text { Faculdade de Biblioteconomia e Comunicação (Fabico) - } \\
\text { UFRGS }\end{array}$ & RS & UFRGS & http://www.ufrgs.br \\
\hline Escola de Comunicação - UFRJ & RJ & UFRJ & http://www.ufrj.br \\
\hline Universidade Federal de Sergipe & SE & UFS & http://www.ufs.br \\
\hline Universidade Federal de Santa Catarina & $\mathrm{SC}$ & UFSC & http://www.ufsc.br \\
\hline Faculdade de Comunicação Social - FACOS - UFSM & RS & UFSM & http://www.ufc.br \\
\hline Universidade Federal de Viçosa & $M G$ & UFV & http://www.ufv.br \\
\hline Universidade Metodista de São Paulo & SP & UMESP & http://www.metodista.br \\
\hline Faculdade de Comunicação - UnB & DF & UNB & http://www.unb.br \\
\hline Faculdade de Arquitetura, Artes e Comunicação - UNESP & $\mathrm{SP}$ & UNESP & http://unesp.br \\
\hline Universidade Católica de Pernambuco & PE & UNICAP & http://www.unicap.br \\
\hline Universidade Metodista de Piracicaba & $\mathrm{SP}$ & UNIMEP & http://www.unimep.br \\
\hline Universidade do Vale do Rio dos Sinos & RS & UNISINOS & http://www.unisinos.br \\
\hline Universidade Sagrado Coração & $\mathrm{SP}$ & USC & http://www.usc.br \\
\hline Universidade Municipal de São Caetano do Sul & SP & USCS & http://www.uscs.edu.br \\
\hline
\end{tabular}


conhecimento conteudos criacao critica cultural curriculares curriculo CUYSO desenvolvimento diferentes digitais disciplinas dominio odcao oducacao emissoras empresas ensino escola estrutura estudantes etica exercicio experimental extensao faculdade fatos formacao totografia graduacao habilitacao interesse internet jornais jOrnalismo jornalista laboratorio meios mercado mida midias muno naconal novas objetivo oferece organizacoes pais perfil pesquisa poilica posgraduacao pratica processos producao professores profissao profissional programas projetos proposta pubico radio realidade redacao rosponsabinidado responsavel revistas servicos SOCIal sociedade tecnicas televisao tempo teorca tv universidade veiculos vioo visao

a amplitude do escopo, valorizando plataformas

- TV, rádio, jornal e internet - e uma visão crítica, pautada por uma formação humanística e cultural a favor da sociedade. Entre os termos, destacam-se ainda os relacionados a atividades acadêmicas e de pesquisa.

Segundo o MEC, a única condição referente à estrutura curricular é: a carga horária das disciplinas específicas não deve ser inferior a 50\% do total. É o Ministério que avalia, de acordo com as ementas, planos de aula e projeto pedagógico, a pertinência entre as disciplinas, além do equilíbrio da carga horária. Matrizes curriculares, planos de ensino e intenções públicas em sites podem funcionar tanto como instrumentos de planejamento oficiais, consonantes com as exigências legais, quanto como argumento 
convincente para futuros alunos. Muitas vezes, se distanciam da realidade em sala de aula. Ainda assim, como lembra CHRISTOFOLETTI (2010), planos e currículos são sinalizadores de estratégias de ensino, de práticas educacionais e políticas formativas. Dessa forma, é possível apontar minimamente a presença de temas ligados às novas tecnologias na formação do jornalista.

Para realizar uma análise quantitativa dos currículos, levou-se em conta uma adaptação da Taxonomia de Bloom, que propõe, em linhas gerais, a organização de currículos de cursos de forma a haver um encadeamento lógico entre as disciplinas, das mais simples às mais complexas, compondo uma escala: conhecimento, compreensão, aplicação, análise, avaliação e síntese. Pesquisadores como Campos e Rocha (2011) percebem que a legislação do Ministério da Educação contempla esta sequência, inclusive para cursos de Jornalismo.
A adaptação sugerida para esta análise parte da mesma divisão proposta por Bernardo e Leão (2012), que agrupou disciplinas em dois grupos: conhecimentos/compreensão e aplicação/análise/ avaliação - grosso modo, temos no primeiro grupo disciplinas de caráter teórico e, no segundo, prático. As autoras entendem que a etapa de síntese, capaz de integrar os dois momentos, ocorre de maneira clara apenas na realização do trabalho de conclusão de curso. 0 Quadro 2 apresenta uma sugestão de categorização, destacando das disciplinas teóricas e práticas as que tratam de novas tecnologias, tendo como base títulos e descrições apresentadas publicamente.

0 objetivo em mostrar 0 espaço dedicado à tecnologia nestes cursos enfrentou a dificuldade para que os dados fossem encontrados com clareza nos sites de cada IES. Além dos formatos de dados e complexidades na estrutura de alguns cursos, são

Quadro 2: Categorização de disciplinas sugerida

\begin{tabular}{|l|l|l|}
\hline \multicolumn{1}{|c|}{ Categoria } & \multicolumn{1}{|c|}{ Descrição } & \multicolumn{1}{c|}{ Exemplos } \\
\hline $\begin{array}{l}\text { CON - Conhecimento/Compreensão: } \\
\text { Humanidades }\end{array}$ & $\begin{array}{l}\text { Disciplinas teóricas gerais, relacionadas } \\
\text { a humanidades }\end{array}$ & $\begin{array}{l}\text { Língua portuguesa, Sociologia, Filosofia, } \\
\text { Antropologia }\end{array}$ \\
\hline $\begin{array}{l}\text { COJ - Conhecimento/Compreensão: } \\
\text { Jornalismo }\end{array}$ & $\begin{array}{l}\text { Disciplinas teóricas relacionadas à } \\
\text { formação do jornalista }\end{array}$ & $\begin{array}{l}\text { Teoria da Comunicação, História do } \\
\text { Jornalismo }\end{array}$ \\
\hline $\begin{array}{l}\text { COT - Conhecimento/Compreensão: } \\
\text { Tecnologia }\end{array}$ & $\begin{array}{l}\text { Disciplinas teóricas voltadas à } \\
\text { compreensão tecnológica }\end{array}$ & $\begin{array}{l}\text { Comunicação digital, novas tecnologias, } \\
\text { cibercultura }\end{array}$ \\
\hline APL - Aplicação/avaliação/análise & $\begin{array}{l}\text { Disciplinas práticas, relacionadas a } \\
\text { plataformas }\end{array}$ & $\begin{array}{l}\text { Fotojornalismo, Radiojornalismo, } \\
\text { Telejornalismo }\end{array}$ \\
\hline $\begin{array}{l}\text { APT - Aplicação/avaliação/análise: } \\
\text { Tecnologia }\end{array}$ & $\begin{array}{l}\text { Disciplinas práticas relacionadas à } \\
\text { internet e tecnologia }\end{array}$ & $\begin{array}{l}\text { Laboratório de jornalismo digital, Redação } \\
\text { on-line }\end{array}$ \\
\hline OPT - Disciplinas optativas & Disciplinas cuja escolha é feita pelo estudante durante o curso \\
\hline TCC - Trabalho de Conclusão de Curso & Elaboração de projeto experimental e monografia \\
\hline
\end{tabular}


poucas que, por exemplo, disponibilizam a ementa e a carga horária de suas disciplinas - nestes casos, marcados no Quadro 3 com um asterisco, a proporção de disciplinas levou em conta sua quantidade, em vez do número de horas.

Há casos em que a presença da Taxonomia de Bloom é evidente: na Universidade Mackenzie, em cada plano de ensino consta qual dos seis níveis de cognição a disciplina se refere. Outras, como a PUC Minas ou a UEPG, adotam, por exemplo, a nomenclatura "disciplinas gerais" e "disciplinas específicas". A situação da UFMG, no entanto, pode servir como parâmetro geral diante dos dilemas e da necessidade em responder às demandas: o curso passou por uma transição curricular em 2010, mantendo duas versões de seu currículo simultaneamente.

Quadro 3: Distribuição de disciplinas em matrizes curriculares
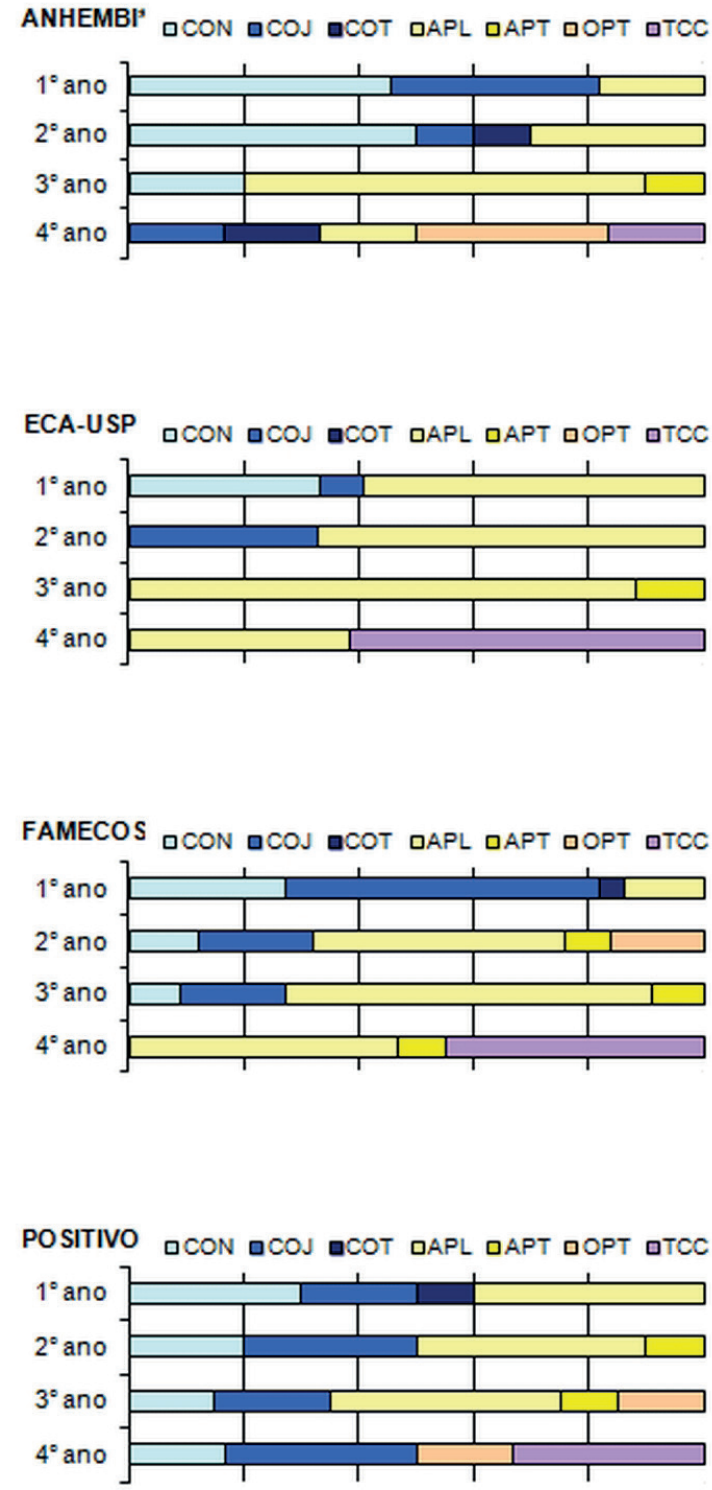
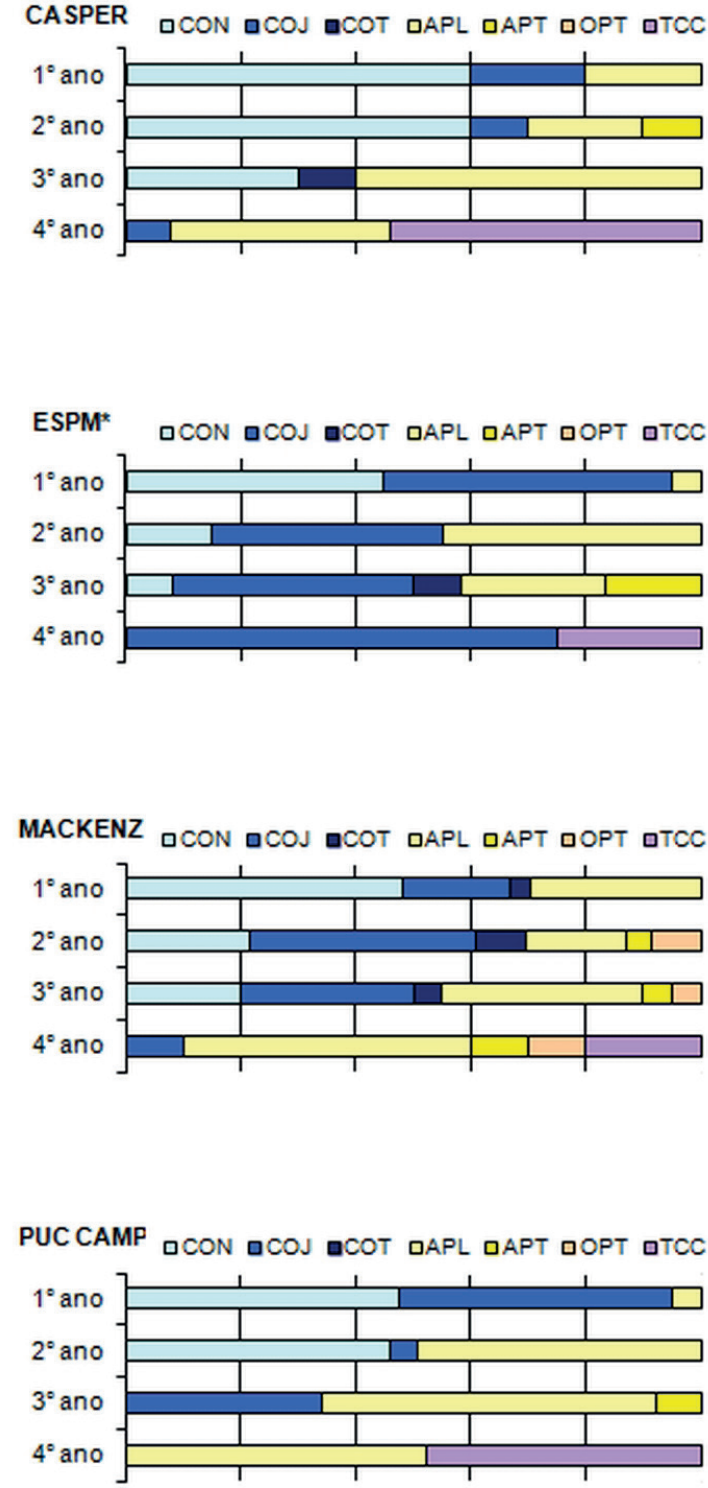
Quadro 3 (continuação)

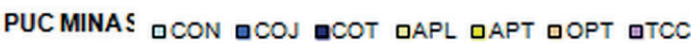

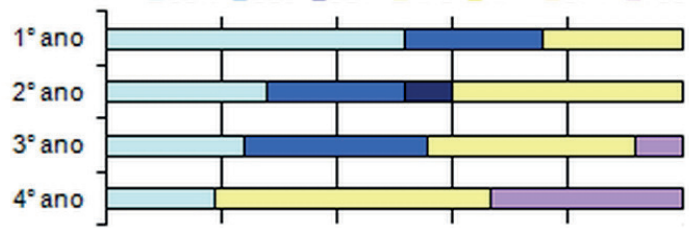

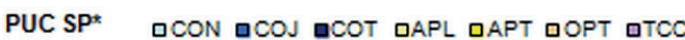

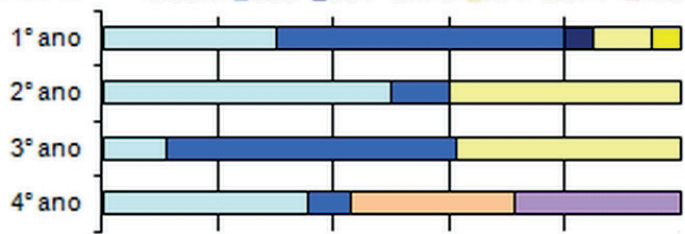

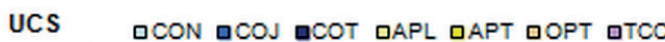

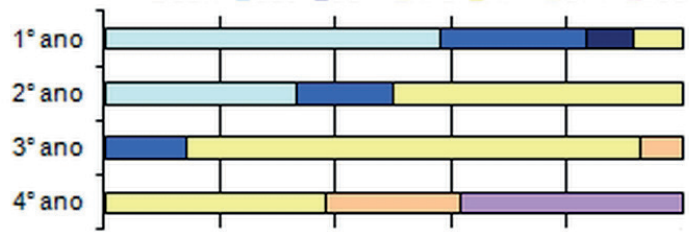

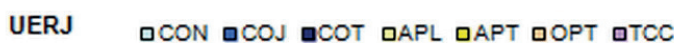

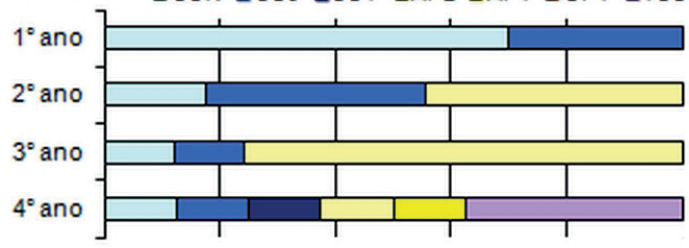

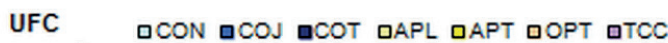
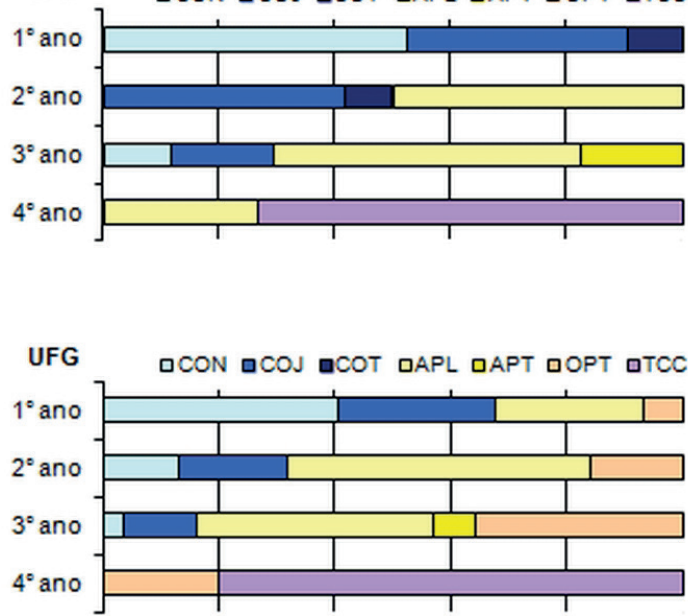

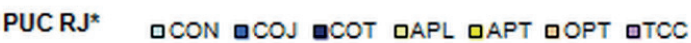
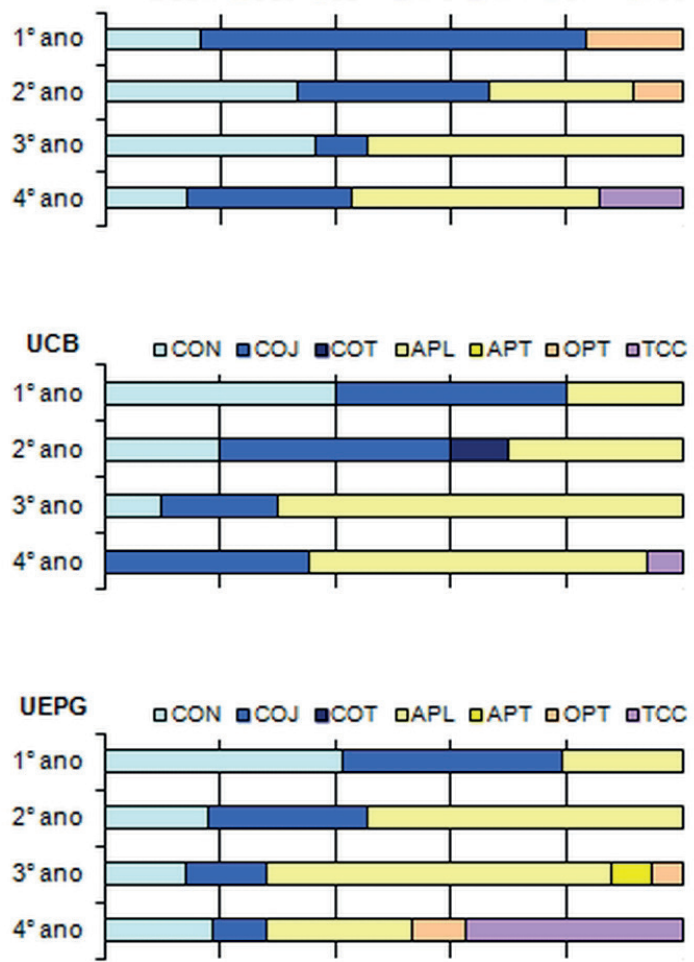

UFBA QCON QCOJ ICOT QAPL DAPT QOPT QTCC
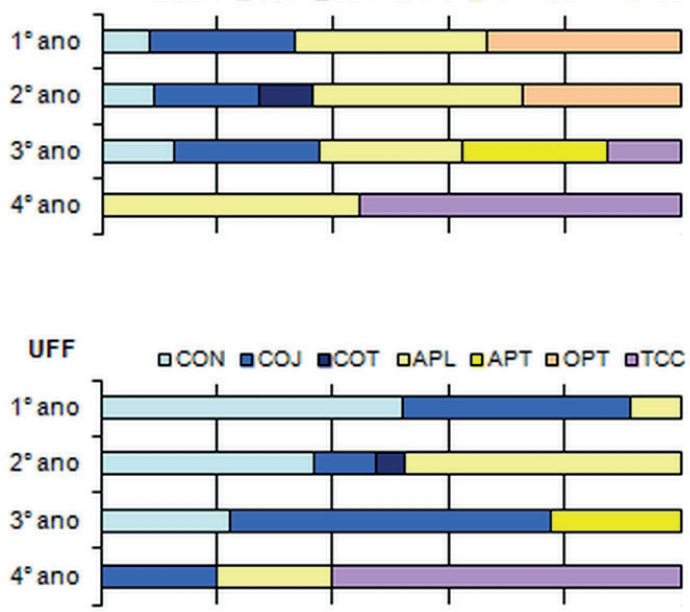

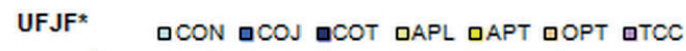

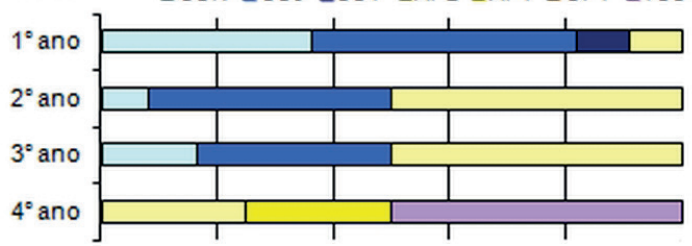




\section{Quadro 3 (continuação)}
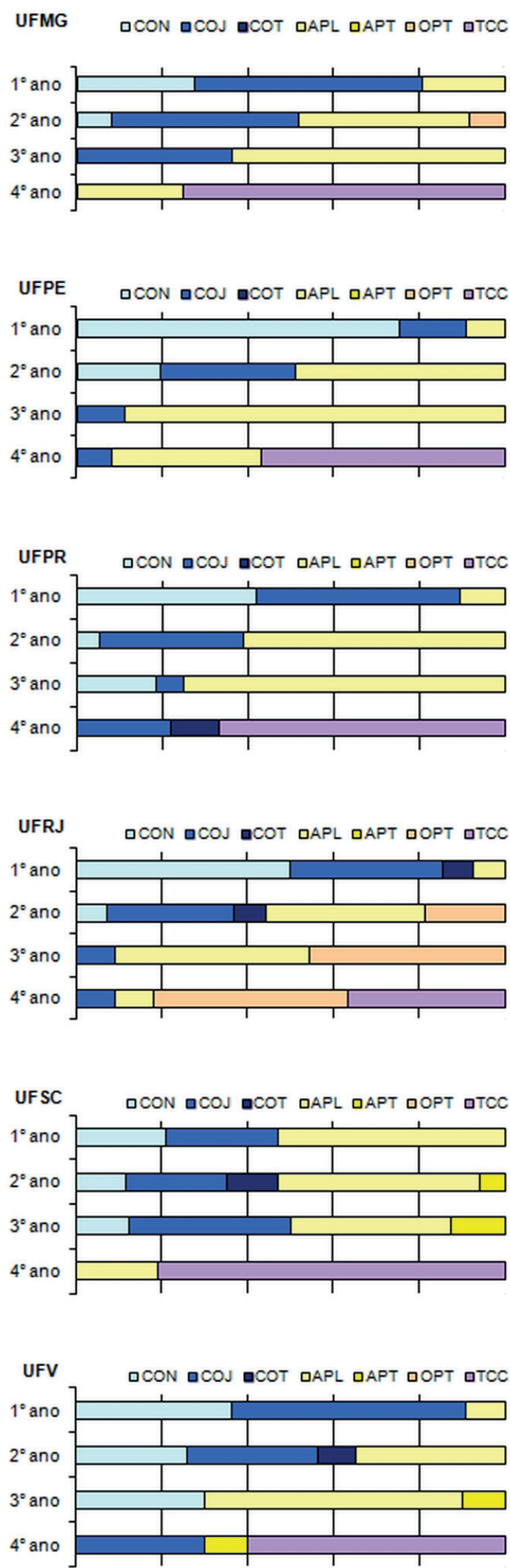
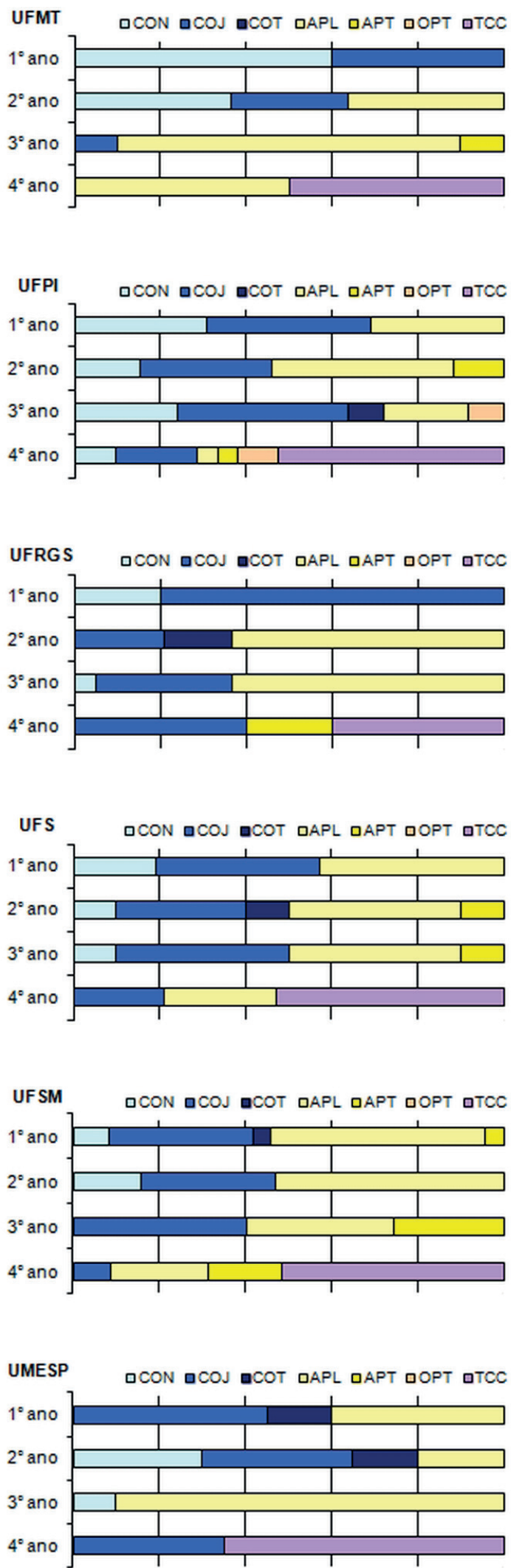


\section{Quadro 3 (continuação)}
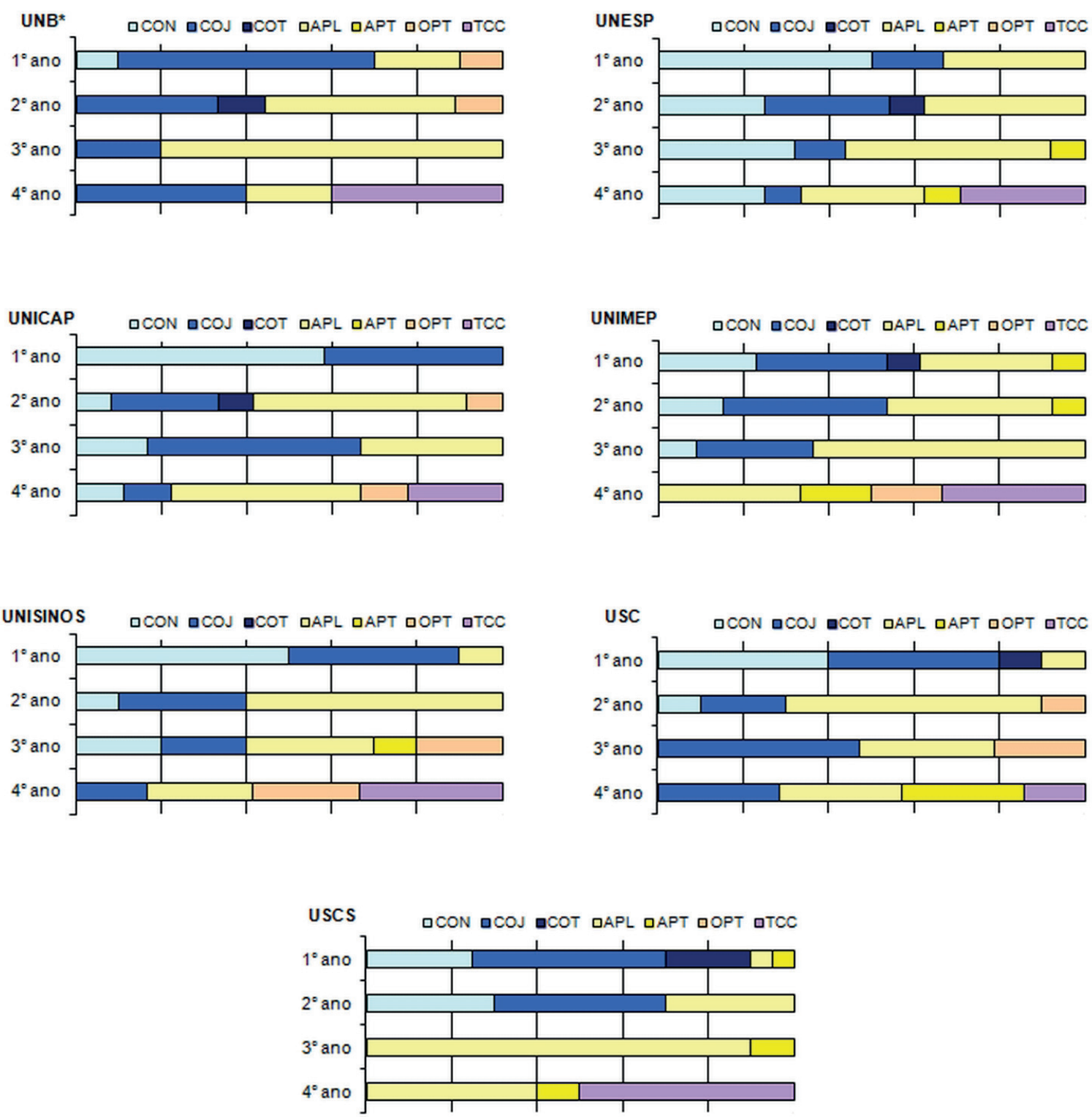

A opção pela visualização anual esconde outra característica: apenas três dos 39 cursos não dividem suas disciplinas por semestres, o que denota um esforço das instituições em apresentar uma variada oferta de assuntos durante quatro anos. De qualquer forma, a Lei de Diretrizes e Bases da Educação Nacional, de 1996, desobriga as universidades a adotarem um currículo mínimo, permitindo a cada faculdade estabelecer seus programas. 0 resultado dessa flexibilização pode ser visualizado no Quadro 3: ainda que seja nítida uma gradativa passagem entre disciplinas teóricas e práticas, seguindo a Taxonomia de Bloom, não há consenso algum entre as proporções desses conteúdos. 


\section{aplicados avanado cibercultura compulacao comunicacao convergencia craseo digitais digital experiencia gestao grafico hipermidia hipertexto hipertextual historia imagem informacao informatica internet jornalismo laboratorio linguagem meios midias matases multimidia novas oficina on-line planejamento politicas portais pratica producao produtos redacao redes sistemas site sociais social sociedade tecnica tecnologia tecnologias teoria webjornalismo}

Outro retrato desta dispersão está na variedade de títulos entre as disciplinas relacionadas à tecnologia. A nuvem de palavras da Figura 2 reúne as 65 palavras utilizadas para a composição de seus títulos. Nota-se a presença reduzida de termos que denotem reflexão mais aprofundada sobre 0 tema - como "inovação" ou "computação". Convém destacar ainda que, enquanto, visualmente, há cursos com mais ou menos disciplinas voltadas para a tecnologia, algumas podem abrir espaço para o tema em momentos não relacionados diretamente aos títulos. É 0 caso da Universidade Metodista, cuja descrição em seu ementário aponta que estudos relacionados à Internet são discutidos nas disciplinas "Comunicação, história e sociedade" e "Jornalismo e imagem".

Algumas instituições - entre elas, UFG, UFBA e UFMG - oferecem em sua grade a possibilidade de cursar disciplinas optativas, de acordo com 0 interesse do aluno. Em Goiás, é preciso optar por uma das três ênfases: pesquisa, mídia impressa ou audiovisual - onde estão incluídas as disciplinas voltadas a "webjornalismo". Já em Minas, as áreas são: criação em comunicação, comunicação das organizações, estudos comunicacionais e produção da notícia. Na instituição baiana, por exemplo, existem opções aplicadas à tecnologia, 
como Comunicação Multimídia e Oficina de Jornalismo Digital, mas ao mesmo tempo opções em humanidades e outras de caráter empreendedor (administração organizacional jornalística) ou artística (cinema internacional e quadrinhos, por exemplo).

Tal opção, que pode representar uma alternativa para contemplar perfis de formação tão distintos, pode encontrar dificuldades estruturais. É 0 caso da Escola de Comunicações e Artes da USP, que também oferece disciplinas optativas, mas adverte: "0 mercado de trabalho tem cobrado dos egressos conhecimentos mais amplos em especialidades que não contam com docentes com domínio suficientemente seguro para oferecer disciplina em áreas emergentes", ao mesmo tempo em que pressupõem que "os ingressantes têm conhecimento suficiente em determinadas áreas técnicas não necessitando de conteúdos que antes estavam contidos em disciplinas oferecidas".

Em contrapartida a essa visão, existem cursos que dão ênfase a ferramentas Web - a matriz da Universidade de São Caetano do Sul apresenta disciplinas como "Redes Sociais", "Mídias digitais" e "Convergência das Mídias". Em outra instituição pesquisada, a Universidade do Vale do Rio dos Sinos, há uma graduação específica em Comunicação Digital $^{15}$, que propõe integrar conhecimentos das áreas de tecnologia da informação, marketing, gestão, comunicação e artes.

\section{Considerações Finais}

Com o cenário apresentado a partir das demandas profissionais, das discussões relacionadas ao futuro da profissão e das iniciativas que aproximam jornalistas dos conhecimentos mais aprofundados em programação de computadores, o Jornalismo se movimenta por caminhos delineados pela evolução tecnológica. Ao observar os currículos das instituições apontadas como as melhores do Brasil, verifica-se a intenção de oferecer ao futuro profissional um amplo escopo disciplinar, buscando formas de relacionar visão crítica com domínio e prática dos ambientes de produção do Jornalismo. No entanto, a profusão de nomenclaturas e abordagens denota a dificuldade em estabelecer esta relação no campo das tecnologias digitais conectadas. Nas grades analisadas, não é possível apontar com clareza espaços nitidamente definidos para reflexões sobre a evolução tecnológica no campo do Jornalismo, seus impactos na produção de relevância de informação social e ensino das adaptações necessárias nas habilidades dos futuros profissionais.

A pesquisa constatou ainda que a ênfase das disciplinas observadas possui abordagem instrumentalista. Ou seja, ensino somente de ferramentas acessíveis a todos que utilizam a Internet de forma doméstica, sem profundidade na apropriação tecnológica, como 
a aprendizagem do uso de mídias digitais. 0 impacto da aprovação das novas diretrizes curriculares, que deve resultar em novos ajustes curriculares a partir de 2015, é uma oportunidade para revisar esta postura.

A partir das informações coletadas, apontamos que os cursos superiores em Jornalismo, no campo do ensino das tecnologias digitais, se esforçam para se adaptar às demandas profissionais e informativas da sociedade contemporânea. Ao mesmo tempo, acreditamos que o caminho seja a introdução do ensino destas tecnologias de modo multidisciplinar, como se vê em iniciativas identificadas tanto em redações quanto em instituições de ensino no exterior. Do contrário, ao não estimular o pensamento e a apropriação das tecnologias de maneira mais aprofundada, diante dos efeitos destas transformações, há um risco deste profissional se distanciar do espaço de importância e referência social. Neste momento, o descolamento do curso ao guarda-chuva da Comunicação Social com a aprovação das diretrizes abre uma oportunidade para valorizar a importância do domínio tecnológico na esteira da discussão de projetos pedagógicos.

\section{Referências}

ALBUQUERQUE, A. DE. A identidade jornalística no Brasil: algumas questões teóricas e metodológicas. E-compós, v. 1, p. 1-14, 2004.

ANDERSON, C. W.; BELL, E.; SHIRKY, C. PostIndustrial Journalism: Adapting to the Present. Disponível em: < http://towcenter.org/research/postindustrial-journalism $>$.
BARAN, P. On distributed communications.

Memorandum prepared for United States Air Force Project Rand, 1964.

BERNARDO, C. H. C.; LEÃO, I. B. Análise das matrizes curriculares dos cursos de Comunicação Social com habilitação em Jornalismo no Brasil: um retrato da realidade nacional. Intercom - Revista Brasileira de Ciências da Comunicação, v. 35, n. 1, p. 253-274, 2012. BERRY, D. M. The computational turn: Thinking about the digital humanities. Culture Machine, v. 12, p. 1-22, 2011. BRIGGS, M. Journalism Next. Washington, DC: CQ Press, 2010.

CAMPOS, P.; ROCHA, E. Ensino de Jornalismo: perfil profissional, regionalização das habilidades técnicas e competências. Conexão - Comunicação e Cultura, v. 10, n. 19, 2011.

CHRISTOFOLETTI, R. Ensino de deontologia jornalística: um olhar sobre os currículos dos cem cursos mais antigos do país. Revista Líbero, v. 13, n. 26, p. 91-102, 2010.

DAGIRAL, É.; PARASIE, S. Portrait du journaliste en programmeur: l'émergence d'une figure du journaliste "hacker."Les Cahiers du Journalisme, n. 22/23, p. 144-155, 2011.

DIB, S. K.; AGUIAR, L. A.; BARRETO, I. Economia política das cartografias profissionais: a formação específica para o jornalismo. XIX Encontro da Compós. Anais...Rio de Janeiro: 2010

FULLER, J. What is Happening to News. Chicago: The University of Chicago Press, 2010.

GENRO FILHO, A. 0 Segredo da Pirâmide: Para uma teoria marxista do jornalismo. Porto Alegre: Tchê! Editora, 1987.

HAMILTON, J. T.; TURNER, F. Responsabilidad mediante algoritmos: reflexiones sobre la construcción automatizada de la información. Infoamérica ICR, v. 2, n. 2 , p. 149-164, 2010. 
KOVACH, B.; ROSENSTIEL, T. Os elementos do jornalismo: o que os jornalistas devem saber e o público exigir. São Paulo: Geração Editorial, 2003.

KUNCZIK, M. Conceitos de Jornalismo: Norte e Sul. São Paulo: Edusp, 1997.

LIMA JUNIOR, W. T. Mídia digital: o vigor das práticas jornalísticas em um novo espaço. [S.l.]

Escola de Comunicação e Artes da Universidade de São Paulo, 2003. . Jornalismo computacional em função da "Era do Big Data". Revista Líbero, v. 14, n. 28, p. 45-52, 2011. . Big Data, Jornalismo

Computacional e Data Journalism: estrutura, pensamento e prática profissional na Web de dados. Estudos em Comunicação, n. 12, p. 207-222, 2012.

MEDITSCH, E. Crescer para os lados ou crescer para cima: 0 dilema histórico do campo acadêmico do jornalismo. Biblioteca Online de Ciências da Comunicação, 1999. Disponível em: <http://bocc.ufp. pt/pag/meditsch-eduardo-dilema-historico-jornalismo. pdf > . Acesso em: 25 jan. 2013

\section{RAMADAN, N. N. A. Jornalismo na Era Digital:}

Construindo uma Filosofia de Ensino. Meeting of the Latin American Studies Association. Anais...Las Vegas, NV: 2004

ROYAL, C. The Journalist as Programmer: A Case Study of The New York Times Interactive News Technology Department. International Symposium in Online Journalism. Anais...Austin, TX: 2010

ZANCHELLI, M.; CRUCIANELLI, S. Integrating Data Journalism into Newsrooms. Disponível em: < http:// www.icfj.org/resources/integrating-data-journalismnewsrooms $>$. 


\begin{tabular}{|c|c|}
\hline $\begin{array}{l}\text { Technological skills and } \\
\text { brazilian higher education: } \\
\text { observation of contemporary } \\
\text { requirements and their } \\
\text { contrast with the curriculum }\end{array}$ & $\begin{array}{l}\text { Habilidades tecnológicas y la } \\
\text { educación superior brasileña } \\
\text { en periodismo: la observación de } \\
\text { las necesidades contemporáneas } \\
\text { y su contraste con los programas } \\
\text { de estudios }\end{array}$ \\
\hline $\begin{array}{l}\text { Abstract } \\
\text { The paper aims to change in news production routines } \\
\text { required by technological developments, connecting } \\
\text { them to current structures of journalism courses. } \\
\text { For that, we analyzed the institution's curriculum, } \\
\text { identified as the best by specialized rankings. The } \\
\text { article concatenates the concepts about what is } \\
\text { necessary of concepts on what is necessary to educate } \\
\text { a professional in Journalism, having the background } \\
\text { of the development of theory of Journalism in the } \\
\text { country and the borders with the multiple possibilities } \\
\text { of professional performance. We concluded that the } \\
\text { professionals, producing relevant information in a } \\
\text { digital technologies ecosystem, are moving away from } \\
\text { the importance of space and social reference because } \\
\text { of the home use of technologies. } \\
\text { Keywords } \\
\text { Journalism. Technology. Education. }\end{array}$ & $\begin{array}{l}\text { Resumen } \\
\text { El artículo destaca los cambios en las rutinas de } \\
\text { producción de noticias presentadas por los avances } \\
\text { tecnológicos, relacionándolos con la estructura actual } \\
\text { de los cursos de periodismo. Con este fin, hubo un } \\
\text { reconocimiento del plan de estudios en las mejores } \\
\text { instituciones identificadas en listados especializados. } \\
\text { Proporciona una visión general de ideas sobre lo que } \\
\text { se necesita para la formación de profesionales en } \\
\text { el periodismo, con el fondo de el desarrollo de una } \\
\text { Teoría del Periodismo en Brasil y en las fronteras con } \\
\text { las múltiples posibilidades de actuación profesional. } \\
\text { Se concluye que el profesional de la producción } \\
\text { de información socialmente relevante en las } \\
\text { tecnologías digitales conectadas se está alejando de la } \\
\text { importancia y el espacio social de referencia, debido a } \\
\text { su uso de forma doméstica. } \\
\text { Palabras clave }\end{array}$ \\
\hline
\end{tabular}

